Original Paper

\title{
Ventriculosubgaleal shunting in the treatment of posthemorrhagic hydrocephalus of premature
} infants: case series

\author{
Alexandre Canheu ${ }^{1}$ \\ Received: 16 April 2020 / Published: 31 January 2021
}

\begin{abstract}
Introduction: Posthemorrhagic hydrocephalus $(\mathrm{PHH})$ comprises the most common complication in those preterm infants (PTI) who suffered germinative matrix hemorrhage $(\mathrm{GMH})$, and its treatment is still matter of controversies. These infants usually weigh less than $1,500 \mathrm{~g}$ and a temporary CSF diversion device is needed. VSGS is preferred in those cases because it is a simple and rapid method, no need for repetitive aspiration for the evacuation of CSF, gives a permanent decompression without causing electrolyte and nutritional losses, and still protects the cerebral development of newborns with $\mathrm{GMH}$.

Methods: We analyzed a series of $22 \mathrm{PTI}$ who underwent VSGS for $\mathrm{PHH}$, between July 2015 and April 2019, and minimum follow-up 6 months. The median gestation age was 28 weeks (range 23-32). The median weigh was $985 \mathrm{~g}$ (range 625-1615). The mean period harboring de VSGS was 61,8 days (range 35-80). Results: The cases were studied for: 1) Shunt dependency: 11 children (50\%) showed persistent hydrocephalus at further investigation and underwent to VP shunt after stable clinical condition. 2) Infection: 6 subjects $(27,2 \%)$ showed positive cultures, and were converted to External Ventricular Device (EVD), and further VP shunt; 3) Outcome: the results were separated in Excellent/Good (GOS 5-4) 12 subjects (54\%); Poor (GOS 3$2)$ : 8 subjects (36\%) and Death (GOS 1): 2 subjects (10\%). Conclusions: VSGS is a good alternative method to treat $\mathrm{PHH}$, especially in a preterm infant who needs a temporary shunt device. The low rate of severe complications and encouraging results about persistent hydrocephalus should guide further investigation and larger cases series.
\end{abstract}

Key words: Ventriculosubgaleal shunting, Subgaleal shunting, Preterm infants, Intraventricular hemorrhage, Posthemorrhagic hydrocephalus

${ }^{1}$ Division of Neurosurgery, State University of Londrina, Londrina, PR, Brazil

To whom correspondence should be addressed: Alexandre Canheu, MD [E-mail: alexandrecanheu@gmail.com]

Journal homepage: www.sbnped.com.br

\section{Introduction}

Intraventricular hemorrhage (IVH) remains a serious complication of premature birth. Despite many treatment options, there is still no consensus on the management of post-hemorrhagic hydrocephalus $(\mathrm{PHH})$ in the very low birth weight (VLBW) baby $[1,2,5,8]$. Preterm infants (PTI) are at risk for an extensive array of neurological complications, of which the most commonly observed and severe is intraventricular hemorrhage (IVH). Currently, IVH is seen in approximately $15 \%-20 \%$ of infants weighing below $1500 \mathrm{~g}$ and in $50 \%$ of infants weighing less than $750 \mathrm{~g}$. In $25 \%-50 \%$ of cases, progressive posthemorrhagic ventricular dilatation and posthemorrhagic hydrocephalus $(\mathrm{PHH})$ develop as result of IVH. Symptomatic PHH has been associated with poor outcomes, including elevated rates of cognitive deficits, disability, and mortality [4]. Many reports have been showing VSGS as a beneficial tool in the management of $\mathrm{PHH}$ on premature infants before the placement of a permanent shunt and also comparing VSGS with Omaya Reservoir (OR) technique. The preference of these two techniques has been seen in different neurosurgical centers [5], although no significant statistical difference has been demonstrated in general outcomes between the both of them [6]. Since VSGS offers a less handling of the system and a constant control of intracranial hypertension, it remains to be the preferred protocol for the author, because puncturing the reservoir to control intracranial pressure daily does not seem necessary. Moreover, other authors have attempted to show that these VSGS patients were significantly older, had achieved greater weights and more optimal surgical candidacy at the time of VP shunt insertion $[3,5]$. We herein investigate the role of VSGS in the prognosis of the many complications it can occur.

\section{Material and methods}

We analyzed a series of $22 \mathrm{PTI}$ who suffered Papile [7] grades III and IV of IVH and underwent VSGS for PHH, between July 2015 and April 2019. All 


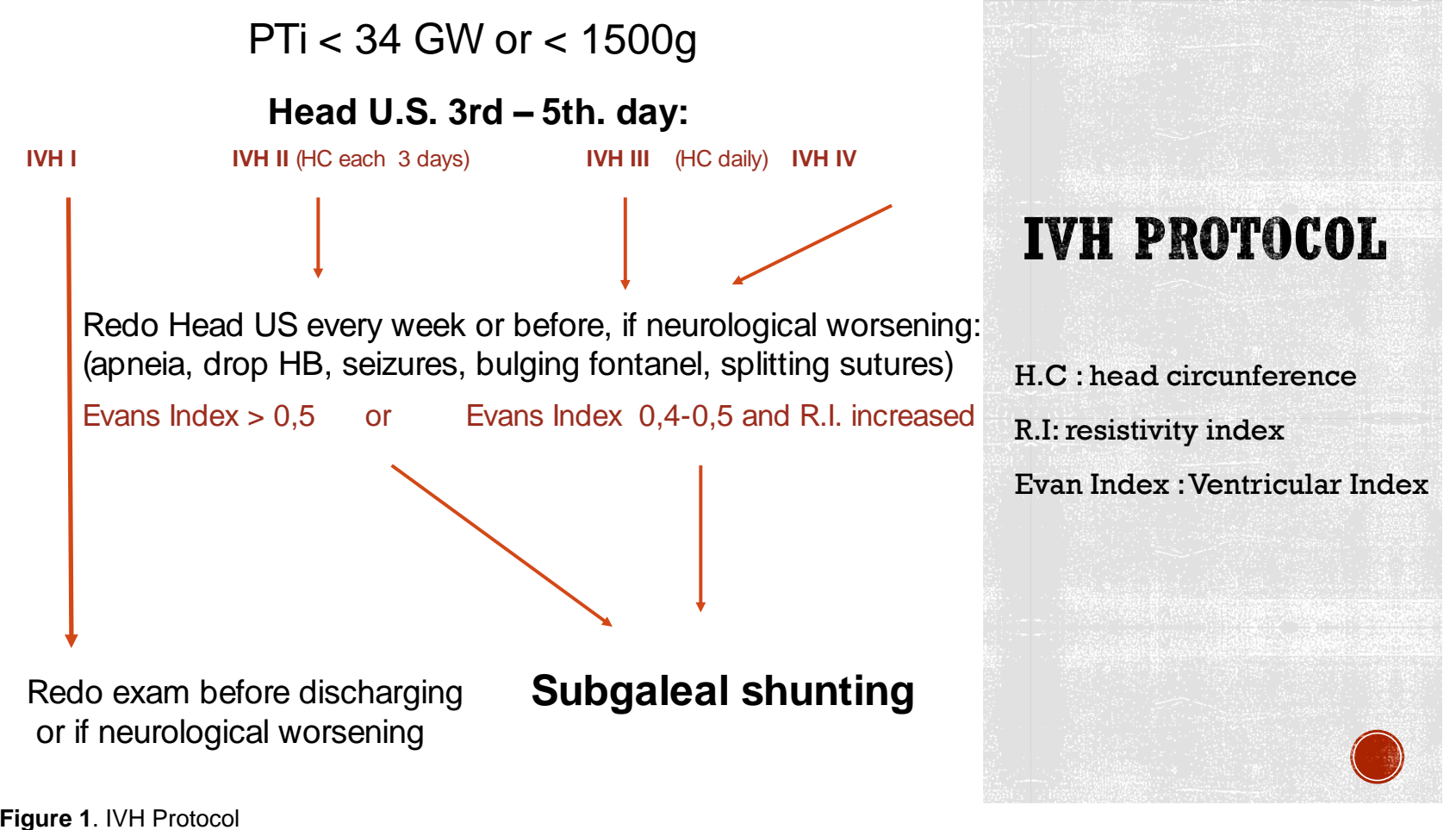

Figure 1. IVH Protocol

subjects had a minimum of 9-month follow-up. The median gestation age was 28 weeks (range 23-32). The median weight was $985 \mathrm{~g}$ (range 625-1615). The mean period harboring de VSGS was 61,8 days (range 35-80).

\section{Diagnosis}

$\mathrm{GMH}$ and $\mathrm{PHH}$ were diagnosed upon serial head ultrasounds $(\mathrm{HU})$ performed by the senior author at side bed into de Neonatal ICU. All the cases were classified into Papile et al grade groups (table 1).

Table 1. Papile's classification of preterm intraventricular hemorrhage

\begin{tabular}{l|l}
\hline Papile Classification & \\
\hline Grade I & Hemorrhage limited to the GM \\
Grade II & IVH but no ventricular dilatation \\
Grade III & IVH and ventricular dilatation \\
Grade IV & IVH and parenchymal hemorrhage \\
\hline
\end{tabular}

The subjects were also studied pre-operatively for: gender, gestation weeks, weight at birth, age at surgery (in days), APGAR, and post-operatively for: days harboring the system, infection and shunt dependency. The follow-up protocol for IVH is summarized in figure 1. All the grades III and IV were seek with HU weekly, or sooner as it needed, as well daily for measurements of head circumference $(\mathrm{HC})$, fontanel fashion, and clinical general status. Once the patients fit the profile established by the strict protocol (figure 1), the PTI had to be operated. We discussed the clinical status and coagulation exams with the ICU crew and if necessary, red blood cells or platelets transfusion were available.

\section{Surgical Technique}

All the PTI were transferred to the operation room and under general anesthesia, the skin was incised and subgaleal space undermined. A small trephination at Kocher point was made and the ventricular catheter inserted. A valveless system (HpBio® - neonatal) was then connected (figures 2) without a distal catheter (removing the valve). The skin was closed in one layer fashion with separated non-absorbable sutures.

\section{Post-operative period}

In the ICU, all the PTI were followed daily with $\mathrm{HC}$ measurements and wound inspection twice a day. We recommended the nurses to do a massage several times a day upon the system reservoir, to guarantee a good subgaleal pouch, especially in the first five days post-op. Effort was also taken not to put tight dressings over the wound, avoiding the stretch of the subgaleal pouch. Head Ultrasound continued to be done weekly to follow de ventricular size and brain arteries Doppler fashion [8].

\section{Results/Discussion}

The subjects are being followed at least for 9 months since each surgery. Every studied detail is summarized in table 2 . 
Table 2. Cases series numbers and results

\begin{tabular}{|c|c|c|c|c|c|c|c|c|}
\hline $\begin{array}{c}\text { CASE } \\
\text { NUMBE } \\
\text { R }\end{array}$ & G.W. & $\begin{array}{l}\text { PAPILE } \\
\text { GRADE }\end{array}$ & $\begin{array}{c}\text { AGE AT } \\
\text { SGS } \\
\text { (DAYS) }\end{array}$ & WEIGHT(G) & $\begin{array}{l}\text { DAYS } \\
\text { WITH } \\
\text { SGS }\end{array}$ & $\begin{array}{c}\text { INFECTIO } \\
\mathbf{N}\end{array}$ & $\begin{array}{l}\text { CONVERTION } \\
\text { TO VP SHUNT }\end{array}$ & OUTCOME \\
\hline 1 & 25 & IV & 20 & 780 & 50 & $\mathrm{~N}$ & $Y$ & EXCELENT \\
\hline 2 & 28 & IV & 15 & 850 & 45 & $\mathrm{~N}$ & Y & EXCELENT \\
\hline 3 & 24 & IV & 10 & 683 & 80 & $\mathrm{~N}$ & $\mathrm{~N}$ & REGULAR \\
\hline 4 & 23 & IV & 12 & 625 & 20 & $\mathrm{~N}$ & $\mathrm{~N}$ & DEATH \\
\hline 5 & 26 & IV & 12 & 905 & 40 & $Y$ & $Y$ & POOR \\
\hline 6 & 31 & III & 30 & 1105 & 70 & $\mathrm{~N}$ & $\mathrm{~N}$ & EXCELENT \\
\hline 7 & 30 & IV & 25 & 1085 & 70 & $\mathrm{~N}$ & $\mathrm{~N}$ & EXCELENT \\
\hline 8 & 29 & III & 12 & 890 & 75 & $\mathrm{~N}$ & $\mathrm{~N}$ & POOR \\
\hline 9 & 29 & IV & 13 & 780 & 77 & $\mathrm{~N}$ & $\mathrm{~N}$ & POOR \\
\hline 10 & 30 & III & 15 & 1050 & 63 & $\mathrm{~N}$ & $\mathrm{~N}$ & EXCELENT \\
\hline 11 & 32 & III & 16 & 985 & 65 & $\mathrm{~N}$ & $\mathrm{~N}$ & GOOD \\
\hline 12 & 28 & IV & 12 & 995 & 85 & Y & Y & REGULAR \\
\hline 13 & 30 & IV & 14 & 1615 & 70 & $\mathrm{~N}$ & $\mathrm{~N}$ & GOOD \\
\hline 14 & 26 & IV & 11 & 980 & 40 & $\mathrm{~N}$ & $Y$ & GOOD \\
\hline 15 & 24 & IV & 11 & 650 & 60 & $\mathrm{~N}$ & $\mathrm{~N}$ & GOOD \\
\hline 16 & 25 & III & 12 & 765 & 45 & Y & $Y$ & REGULAR \\
\hline 17 & 25 & IV & 14 & 960 & 40 & $\mathrm{~N}$ & $Y$ & GOOD \\
\hline 18 & 27 & IV & 21 & 1050 & 58 & $\mathrm{~N}$ & $Y$ & GOOD \\
\hline 19 & 29 & IV & 10 & 1105 & 30 & $Y$ & $Y$ & POOR \\
\hline 20 & 26 & IV & 12 & 675 & 48 & Y & $Y$ & POOR \\
\hline 21 & 30 & IV & 15 & 900 & 70 & $\mathrm{~N}$ & $Y$ & EXCELENT \\
\hline 22 & 28 & IV & 10 & 1010 & 52 & Y & $Y$ & DEATH \\
\hline
\end{tabular}

G.W: gestation weeks, SGS: Subgaleal Shunting, VP shunt: Ventriculoperitoneal shunt, Y: yes, N: no

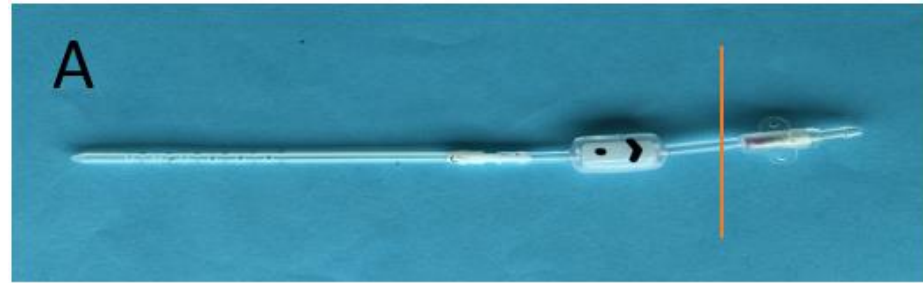

B



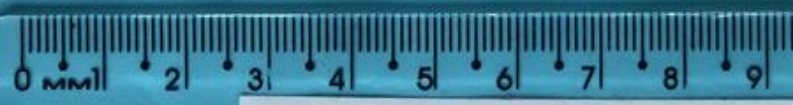

Figure 2. Ventricular catheter connected to the valve system. A. The crossing orange line shows the point the valve is cut off. $B$. The ready system showing the little reservoir and tinny distal end

\section{Shunt dependency}

Six children (27.2\%) developed some sort of complication in which was necessary to perform neuroendoscopic approaches such as septostomy, endoscopic third ventriculostomy, and cysts fenestrations. All of them needed to be converted to a further VP shunt. Other 6 subjects showed persistent hydrocephalus during their investigation and had to undergo a VP shunt after stable clinical condition.

To be prone to VP conversion all the following conditions were necessary: 1) weight higher than $2,000 \mathrm{~g}$, so that PTI's VP shunt would have its chances improved to work properly with less abdominal complications; 2) at least 2 serial negative CSF samples for bacteria, to guarantee that the CSF is free of pathogens 3) CSF protein content less than $1 \mathrm{~g}$, expecting this could decrease the risk of mechanical VP shunt malfunctioning and eventually 4) persistent hydrocephalus and bulging subgaleal pouch, assuring the need of permanent shunting.

Wang et al reported surgery for permanent shunting in $10.9 \%$ at 1 month, $43.5 \%$ at 2 months, and $67.4 \%$ at 5 months after VSGS [3]. A recent metaanalysis from Fountain found $60-86 \%$ conversion to VP shunt after VSGS [13]. 


\section{Infection and complications}

Six subjects $(27.2 \%)$ presented positive CSF cultures. They were converted to External Ventricular Device (EVD), received intravenous antibiotics tailored by the antibiograms, and subsequent VP shunt accordingly the above-noted conditions. 3 of those 6 subjects showed leakage from the pouch and then meningitis, which lead to further EVD. The other 3 developed pulmonary infection followed by sepsis and ventriculitis, and also required temporary EVD and were converted to VP shunt.

The infection rate is variable in the literature. Tubb et al reported a $5.9 \%$ infection rate. Staphylococcus aureus and Staphylococcus epidermidis being the main culprits [9] On the other hand Willis et al. reported $66.7 \%$ of infection [10]. Infection rates seem to be related to the age and weight of children. In our series, the median weight was $985 \mathrm{~g}$, less than $1000 \mathrm{~g}$, and maybe one of the reasons in which led to being more prone to infections. In the same way, the median gestation weeks was 28 weeks, less than 30 weeks, another cut-off for poorer prognosis[11].

The most frequent complications of VSGS besides infection are: leakage, kinking of the shunt tubing, and wound breakdown with variables incidences [12].

\section{Outcome}

The results were separated among: Excellent/Good (Glasgow Outcome Scale - GOS - 54) 12 subjects (54\%). Children who are doing wellperforming, adequate or barely normal motor and cognitive skills for the age; Poor (GOS 3-2): 8 subjects $(36 \%)$, in which include children who are underdeveloped, disabled, and shall be dependent to the caregivers for a significant span of life; and Death (GOS 1): 2 subjects (10\%). One death occurred after severe pulmonary infection resulting in sepsis (patient $\mathrm{n} .4$ ) and the other one (patient n.22) after respiratory distress during bronchospasms crises. Vaner et al observed $28 \%$ of mortality in the first month (25 cases of VSGS), related mainly to infection and sepsis [1]. Kutty et al found $14.2 \%$ of mortality ( 1 out of 7 children). The mortality is intrinsically related to the germinative matrix hemorrhage disease and related morbidly of prematurity.

\section{Conclusions}

VSGS is a safe and quick procedure and works as a good alternative method to treat $\mathrm{PHH}$, moreover those PTI whose need a temporary shunt device $[13,14,15,16]$. A proactive IVH protocol should be conducted in each neonatal ICU in order to diagnose and treat these patients in advance these. Multidisciplinary teams should be encouraged to work on such cases since knowledge from different areas is required, as well as engagement from these professionals, who can face this common and challenging condition. Ongoing multicenter prospective studies are being expected to answer many unsolved issues [17]. So far, we recommend VSGS as a useful tool considering its low rate of severe complications and good results about persistent hydrocephalus.

\section{Disclosure Statement}

The author reports no conflict of interest concerning the materials or methods used in this study or the findings specified in this paper.

\section{Funding statement}

None.

\section{References}

1. Köksal V, Öktem S. Ventriculosubgaleal shunt procedure and its long-term outcomes in premature infants with post-hemorrhagic hydrocephalus. Childs Nerv Syst (2010) 26:1505-1515

2. Shooman D, Portess H, Sparrow O. A review of the current treatment methods for posthaemorrhagic hydrocephalus of infants. Cerebrospinal Fluid Research 2009, 6:1.

3. Wang JY, Amin AG, Jallo GI, Ahn ES. Ventricular reservoir versus ventriculosubgaleal shunt for posthemorrhagic hydrocephalus in preterm infants: infection risks and ventriculoperitoneal shunt rate. J Neurosurg Pediatrics 14:447-454, 2014.

4. Riva-Cambrin J, Shannon CN, Holubkov R, Whitehead WE, Kulkarni AV, Drake J, et al. Center effect and other factors influencing temporization and shunting of cerebrospinal fluid in preterm infants with intraventricular hemorrhage. J Neurosurg Pediatrics 9:473-481, 2012

5. Mazzola CA, Choudhri AF, Auguste KI, Limbrick Jr DD, Rogido M, Mitchell $L$, et al. Pediatric hydrocephalus: systematic literature review and evidence-based guidelines. Part 2: Management of posthemorrhagic hydrocephalus in premature infants. J Neurosurg Pediatrics (Suppl) 14:8-23, 2014.

6. Wellons III JC, Shannon CN, Kulkarni AV, Sim TD, Riva-Cambrin J, Whitehead WE, et al. A multicenter retrospective comparison of conversion from temporary to permanent cerebrospinal fluid diversion in very low birth weight infants with posthemorrhagic hydrocephalus. Neurosurg Pediatrics 4: 50-55, 2009

7. Papile LA, Burstein J, Burstein R, Koffler $H$. Incidence and evolution of subependymal and intraventricular hemorrhage: a study of infants with birth weights less than 1,500 gm. J Pediatr. 1978; 92:529-34.

8. de Oliveira RS, Machado HR. Transcranial colorcoded Doppler ultrassonography for evaluation of children with hydrocephalus. Neurosurg Focus 15(4): 
Clinical Pearl 3, 2003.

9. Tubbs RS, Banks JT, Soleau S, Smyth MD, Wellons JC 3rd, Blount JP, Grabb PA, Oakes WJ. Complications of ventriculosubgaleal shunts in infants and children. Childs Nerv Syst. 2005 Jan;21(1):48-51. 10. Willis BK, Kumar CR, Wylen EL, Nanda A. Ventriculosubgaleal shunts for posthemorrhagic hydrocephalus in premature infants. Pediatr Neurosurg. 2005 Jul-Aug;41(4):178-85.

11. Robinson S. Neonatal posthemorrhagic hydrocephalus from prematurity: pathophysiology and current treatment concepts. J Neurosurg Pediatr. 2012 Mar;9(3):242-58. doi: 10.3171/2011.12.PEDS11136. PMID: 22380952; PMCID: PMC3842211.

12. Eid S, Iwanaga J, Oskouian RJ, Loukas M, Jerry Oakes W, Tubbs RS. Ventriculosubgaleal shunting-a comprehensive review and over two-decade surgical experience. Childs Nerv Syst. 2018 Sep;34(9):16391642

13. Sandoval PV, Rosales PH, Hernández DGQ, Naranjo EAC, Navarro VG. Intraventricular hemorrhage and posthemorrhagic hydrocephalus in preterm infants: diagnosis, classification, and treatment options. Child's Nervous System (2019)
35:917-927.

14. Limbrick Jr DD, Mathur A, Johnston JM, Munro $\mathrm{R}$, Sagar J, Inder T, et al. Neurosurgical treatment of progressive posthemorrhagic ventricular dilation in preterm infants: a 10-year single-institution study. J Neurosurg Pediatrics 6:224-230, 2010

15. Fountain DM, Chari A, Allen D, James G. Comparison of the use of ventricular access devices and ventriculosubgaleal shunts in posthaemorrhagic hydrocephalus: systematic review and meta-analysis. Childs Nerv Syst (2016) 32:259-267.

16. Wellons III JC, Shannon CN, Holubkov R, RivaCambrin J, Kulkarni AV, Limbrick Jr DD, et al. Shunting outcomes in posthemorrhagic hydrocephalus: results of a Hydrocephalus Clinical Research Network prospective cohort study. J Neurosurg Pediatr 20:19-29, 2017.

17. Thomale, U., Cinalli, G., Kulkarni, A.V. et al. TROPHY registry study design: a prospective, international multicenter study for the surgical treatment of posthemorrhagic hydrocephalus in neonates. Childs Nerv Syst 35, 613-619 (2019). 